\title{
BASIC CHARACTERISTICS OF WIDMANSTÄTTEN AUSTENITE IN GOES
}

\author{
${ }^{1}$ Kryštof HRADEČNÝ, ${ }^{1}$ Renáta PALUPČíKOVÁ, ${ }^{1}$ Anastasia VOLODARSKAJA, \\ ${ }^{1}$ Vlastimil VODÁREK
}

${ }^{1}$ VSB - Technical University of Ostrava, Faculty of Materials Science and Technology, 17. listopadu 15, Ostrava - Poruba, Czech Republic, EU, krystof.hradecny@vsb.cz

https://doi.org/10.37904/metal.2020.3505

\begin{abstract}
Twin - roll strip casting is an advanced technology for production of thin strips with the thickness of several millimetres. Recent progress in twin - roll strip casting makes it possible to apply this technology for the production of grain oriented electrical steels (GOES). Optimization of technological processing of GOES using this revolutionary technology requires the detailed knowledge about microstructure evolution.

Cooling of GOES thin strips in the $\gamma+\delta$ phase field is accompanied by the formation of austenite in the form of Widmanstätten laths. This paper summarises basic knowledge about the formation and subsequent decomposition of Widmanstätten austenite in GOES thin strips. Attention is paid to nucleation of Widmanstätten austenite, its growth in the matrix of $\delta$-ferrite, pinning of austenite/ferrite interfaces by sulphides, the formation of epitaxial ferrite, partitioning of carbon and finally to the decomposition of Widmanstätten austenite either to pearlite or plate martensite. Phase transformations were studied by a combination of light microscopy, XRD, SEM + EBSD and TEM.
\end{abstract}

Keywords: GOES, Strip casting, Widmanstätten austenite, EBSD

\section{INTRODUCTION}

Strip casting is a modern, efficient and economical technology for production of steel strips with thicknesses in the order of millimeters [1]. Generally, this value is close to the final sheet thickness, so the amount of postcasting steps could be minimized. This fact entails many financial and environmental benefits to the steelmaking industry. Recent development of the strip casting technology makes it possible to apply it for the grain oriented electrical steel (GOES) production.

Recent studies have demonstrated that the microstructure of as-cast GOES sheets can consist of ferrite, pearlite, plate martensite and residual austenite [2-4]. GOES firstly solidify as $\delta$-ferrite, and during following cooling in the $\delta+y$ region a small fraction of austenite and some minor phases precipitate in the parent ferrite. Newly formed austenite is harder than ferrite. Furthermore, a volume shrinkage is caused by $\delta$ to $y$ phase transformation. Austenite laths form patterns with Widmanstätten morphology. At the end of the $\delta+\gamma$ region austenite decomposition to low temperature products occurs. Products of Widmanstätten austenite decomposition depend on the cooling rate, chemical composition and size of austenite laths.

Basic characteristics of Widmanstätten ferrite in steels have been studied widely but little is known about Widmanstätten austenite formation and decomposition mechanisms, morphology and crystallography [5, 6]. This paper summarises basic knowledge about the formation and subsequent decomposition of Widmanstätten austenite laths in GOES thin strips. 


\section{MATERIAL AND EXPERIMENTAL PROCEDURE}

The thin strip was manufactured at TU Claustahl using the horizontal belt casting process [1]. In this case, liquid steel flows from a ladle into a tundish system and is dispensed onto a water-cooled belt. The top surface of the solidifying strip is protected by argon. The calculated cooling rate varies across the thickness of the strip. The calculated cooling rate on the top surface of the strip in the temperature range from $1573 \mathrm{~K}$ to $973 \mathrm{~K}$ was about $2 \mathrm{~K} \cdot \mathrm{s}^{-1}$. The width and thickness of the belt-casted strip was $0.30 \mathrm{~m}$ and $0.014 \mathrm{~m}$, respectively. Chemical composition of the strip is shown in Table 1.

Table 1 Chemical composition of the cast, mass \%

\begin{tabular}{|c|c|c|c|c|c|c|}
\hline $\mathbf{C}$ & $\mathbf{S i}$ & $\mathbf{M n}$ & $\mathbf{S}$ & $\mathbf{C r}$ & $\mathbf{C u}$ & Al \\
\hline 0.034 & 2.81 & 0.06 & 0.024 & 0.20 & 0.15 & 0.002 \\
\hline
\end{tabular}

Microstructure investigations were carried out on longitudinal sections in the middle width, across the whole thickness of the strip. Microstructure evolution during cooling of the solidified strip was studied using a combination of light microscopy (LM), X-ray diffraction (XRD), scanning electron microscopy (SEM), electron backscattered diffraction (EBSD), X-ray microanalysis (EDX) and transmission electron microscopy (TEM). Samples for EBSD analysis in SEM (Quanta $450 \mathrm{FEG}$ ) were prepared by mechanical grinding and polishing, the final polishing was done using colloidal silica. The OIM Analysis ${ }^{\mathrm{TM}}$ software was used for acquisition and indexing of Kikuchi diffraction patterns and for evaluation of the EBSD orientation data. Minor phases were studied in TEM (JEM 2100) on carbon extraction replicas using both selected area electron diffraction and EDX.

\section{RESULTS}

Figure 1 shows image quality (IQ) + high angle ferrite grain boundaries (HAGB) and low angle ferrite grain boundaries (LAGB) map across the whole thickness of the strip. Microstructure across the thickness consisted of coarse ferrite grains and decomposed Widmanstätten austenite laths [4]. Ferrite grains were up to a few millimetres in diameter. However, detailed analysis demonstrated that these coarse ferrite grains were fragmented into a number of subgrains. Figure $\mathbf{2 a}$ shows a detailed inverse pole figure (IPF) map of ferrite grains inside which subgrains are recognizable. The internal misorientation inside the ferrite grain along the line 1 was measured. Figure $\mathbf{2 b}$ shows misorientation profile along the line 1 . It is obvious that point to point misorientation between pairs of neighbouring points was always less than $2^{\circ}$. On the other hand point to origin misorientation along the line 1 was around $13^{\circ}$. Refinement of ferrite grains can be observed at about 14 depth under the top surface of the strip which corresponds to the area of final solidification of the strip.

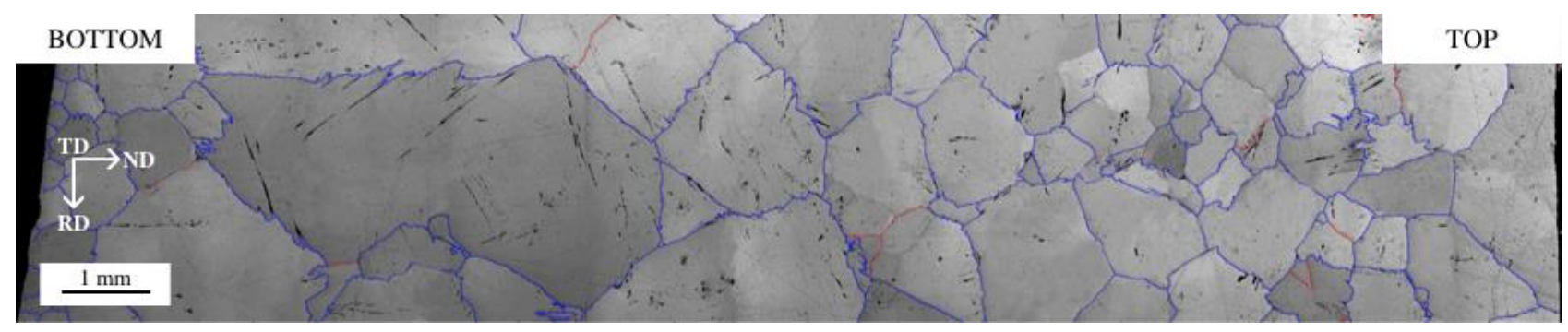

Figure 1 Distribution of decomposed Widmanstätten austenite laths in $\delta$-ferrite across the thickness of the strip, IQ map + HAGB (blue, $\left.\alpha>15^{\circ}\right)+$ LAGB $\left(\right.$ red, $\alpha<15^{\circ}$ ), bottom = bottom surface, top = top surface

The fraction of decomposed Widmanstätten austenite was about $2 \%$ [4]. Laths of Widmanstätten austenite preferentially nucleated at high angle ferrite grain boundaries where they formed low energy flat 
austenite/ferrite interface facets, Figure 3. Laths nucleate directly on HAGB and grow by displacive mechanism with a relatively low rate of growth which allows partitioning of carbon during transformation [3].
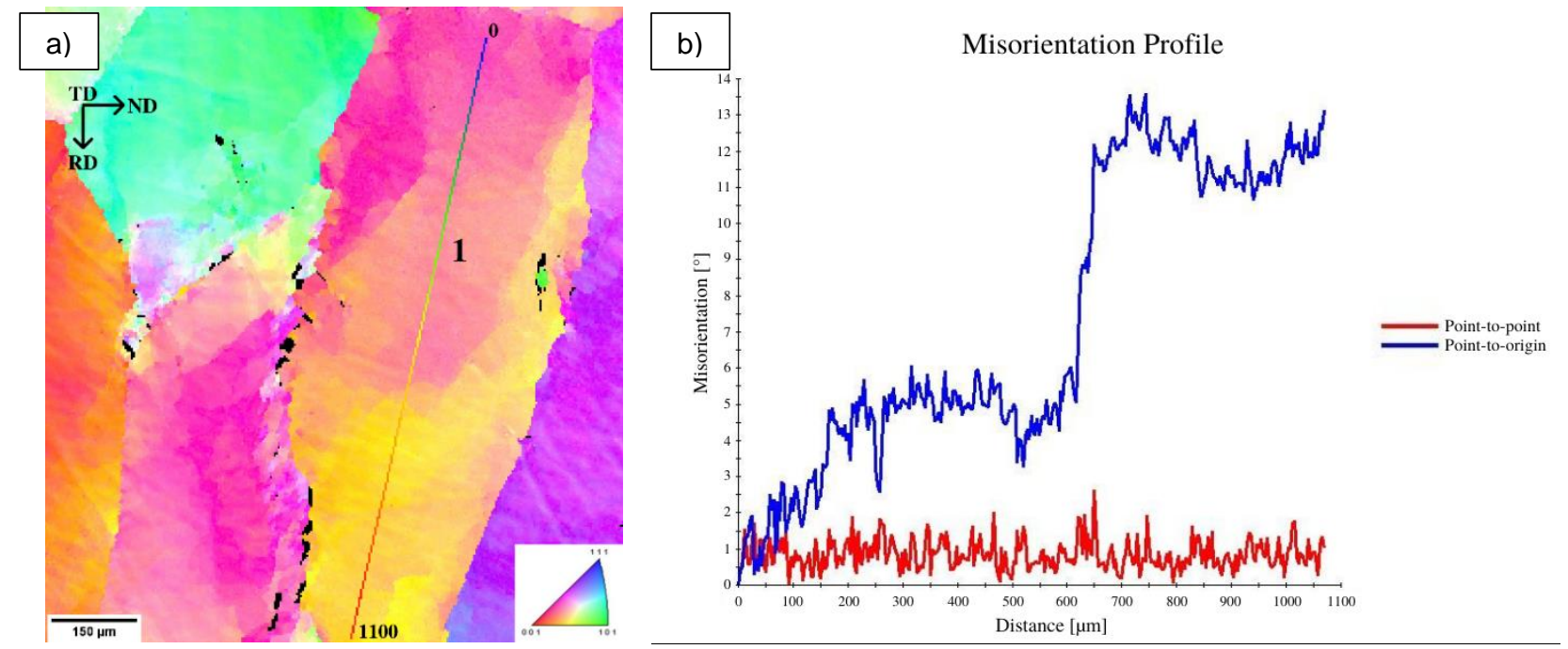

Figure 2 Misorientation inside ferrite grains: a) IPF map with the line 1, b) misorientation profile along the line 1

The formation of Widmanstätten austenite only on one side of a ferrite grain boundary resulted in its straightening, Figure $\mathbf{3 a}$. The reason for straightening is migration of grain boundaries in the vicinity of flat interface facets in order to minimize interfacial energy. It was proved that such straight grain boundaries are actually planar in three dimensions [7]. If Widmanstätten austenite laths nucleated on both sides of a ferrite grain boundary, two sets of flat austenite/ferrite interface facets appeared, Figure $\mathbf{3 b}$. The habit planes of the Widmanstätten laths in two neighbouring ferrite grains generally are not parallel due to the misorientations between these grains. As a result, when laths nucleate on both sides of a boundary, the boundary will be forced to migrate in two opposite directions to accommodate the habit planes of these laths. It resulted in zigzag shape of ferrite grain boundaries composed of alternating segments of straight boundaries, Figure $\mathbf{3 b}$. This was probably favoured by the high formation temperature of Widmanstätten austenite laths [3].

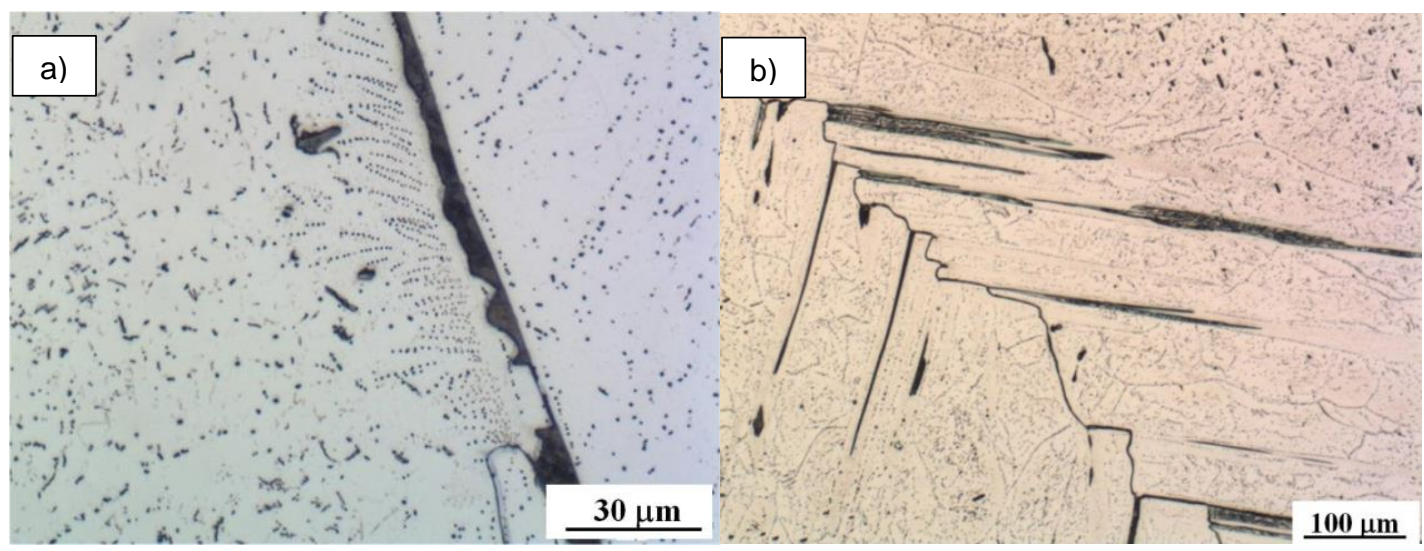

Figure 3 Decomposed Widmanstätten austenite laths nucleated directly on the ferrite grain boundaries a) the straight ferrite grain boundary decorated by decomposed Widmanstätten austenite growing into one

ferrite grain, b) parallel Widmanstätten austenite laths growing into two adjacent ferrite grains, LM

Figures $\mathbf{3 a}$ and $\mathbf{3 b}$ also document heavy precipitation in $\delta$-ferrite. Precipitates occurred along grain and subgrain ferrite boundaries, inside ferrite grains and also close to ferrite/austenite interfaces, Figures $4 a$ 
and $\mathbf{4 b}$. Needle-like precipitates in the ferrite matrix are formed by cementite, Figure $\mathbf{4 b}$. Most fine globular precipitates along grain/subgrain boundaries and in the ferrite matrix are complex sulphides with variable chemical composition. Mostly these sulphides were rich in manganese, chromium, iron and copper [4]. Figure 4c shows typical EDX spectrum of complex sulphides. Chemical composition variability of sulphides indicates that their formation can be expected in a wide range of temperatures [8]. Electron diffraction studies proved that the crystal structure of fine sulphides was consistent with the $\mathrm{Cr}_{2} \mathrm{CuS}_{4}$ phase, Figure $4 \mathbf{d}$ [9].
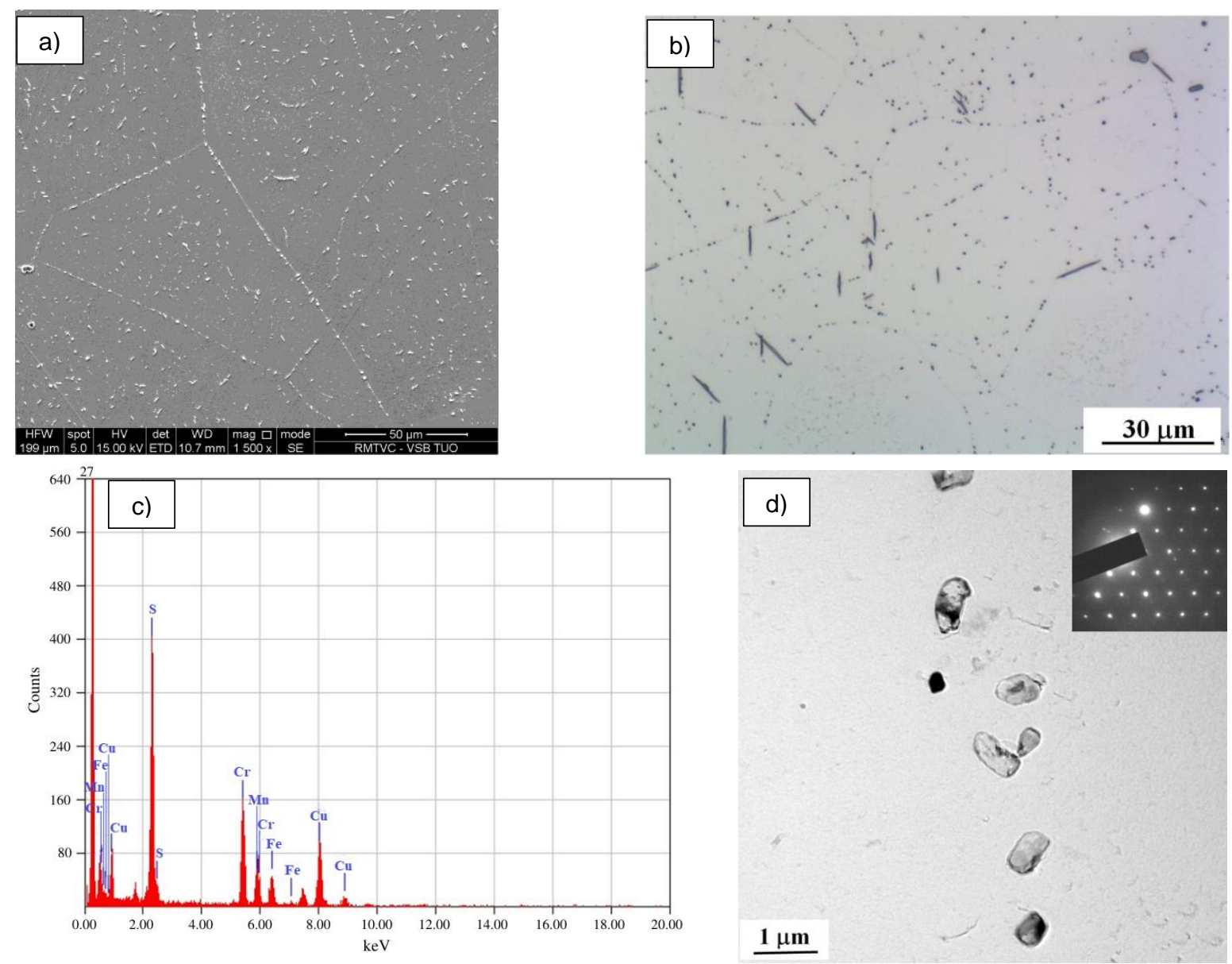

Figure 4 Precipitation in strip casted GOES a) distribution of complex sulphides in ferrite, SEM b) needle-like particles of cementite, fine sulphides along subgrain boundaries, LM, c) EDX spectrum of complex sulphides,

d) Intragranular $\mathrm{Cr}_{2} \mathrm{CuS}_{4}$ sulphides, insert: zone axis [111]cr2Cus4, TEM.

Periodic networks of complex sulphides close to ferrite/austenite interfaces make it possible to investigate the movement of these interfaces at the early stages of Widmanstätten austenite decomposition. Widmanstätten austenite decomposition typically starts with the formation of so-called epitaxial ferrite which predominantly forms close to the tips of Widmanstätten austenite laths [4]. Arrows in Figure 5a define the parts of Widmanstätten austenite laths which transformed to epitaxial ferrite. This "new" ferrite has the same crystallographic orientation as the surrounding ferrite, Figure $\mathbf{5 b}$. The IPF orientation map in Figure $\mathbf{5 b}$ presents parallel decomposed Widmanstätten austenite laths growing from the ferrite grain boundary into the bottom grain. The growth of epitaxial ferrite into flat ferrite/austenite interface facets at ferrite grain boundaries results in a wavy shape of these ferrite grain boundaries [9].

Mechanisms of final austenite decomposition are affected by the differences in the cooling rate across the strip thickness, chemical composition and dimensions of Widmanstätten austenite laths. Products of Widmanstätten austenite laths decomposition are pearlite, plate martensite and retained austenite. In $\mathrm{Fe}-\mathrm{C}$ alloys plate 
martensite appears if they contain more than about 0.6 mass $\%$ [ [10]. The formation of plate martensite during decomposition of Widmanstätten austenite proves that austenite is significantly enriched in carbon. The fraction of retained austenite in the final microstructure of the GOES strip was specified by XRD analysis and reached up to $0.5 \%$. Decomposition of Widmanstätten austenite into pearlite requires enrichment of austenite by carbon to the eutectoid composition. The phase map in Figure 6a shows small areas of retained austenite (green areas) which coexisted with plate martensite. Figure $\mathbf{6 b}$ shows coexistence of plate martensite and perlite.
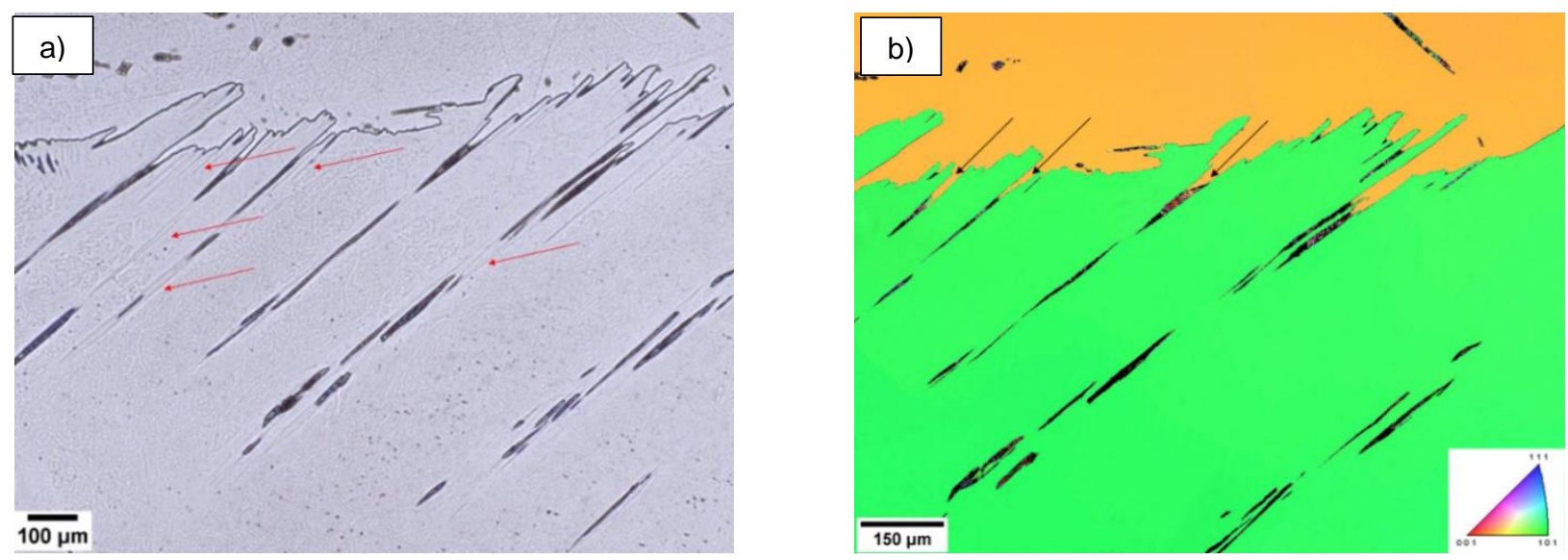

Figure 5 Partial decomposition of Widmanstätten austenite to epitaxial ferrite a) arrows show epitaxial ferrite formed close to the tips of Widmanstätten austenite laths, LM, b) IPF map for ND, arrows mark the growth of epitaxial ferrite from the top grain into the originally flat austenite/ferrite interface facet
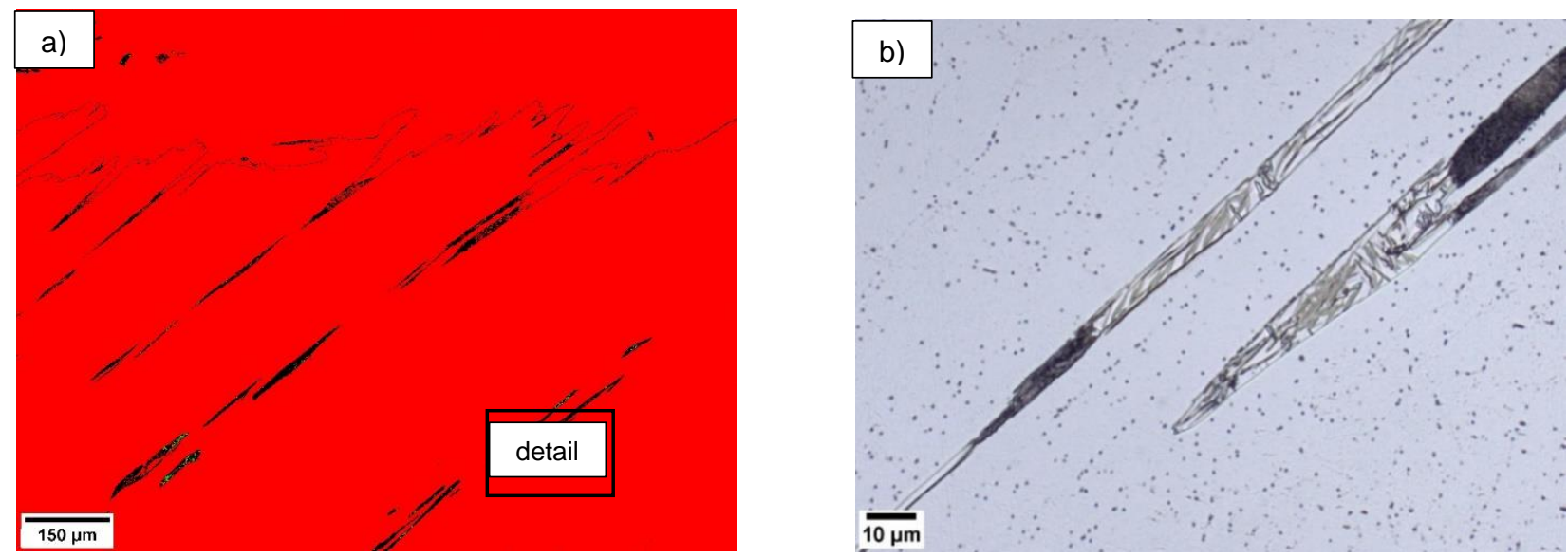

Figure 6 Partial decomposition of Widmanstätten austenite to pearlite, plate martensite and retained austenite a) phase map of ferrite (red) and retained austenite (green), b) detail of Figure $6 \mathbf{a}$, mixture of plate martensite, retained austenite and perlite, LM

\section{CONCLUSION}

Basic knowledge about the formation and subsequent decomposition of Widmanstätten austenite in GOES thin strips can be summarised as follows:

- $\quad$ Solidification of the belt-casted strip started with the formation of the $\delta$-ferrite from liquid steel. Ferrite grains were up to a few millimetres in diameter. However, these grains were fragmented into a number of subgrains.

- $\quad$ During cooling a small fraction (about $2 \%$ ) of Widmanstätten austenite precipitated in the $\delta$-ferrite by displacive mechanism accompanied by partitioning of carbon. Widmanstätten austenite laths 
preferentially nucleated on HAGB and formed the flat low energy austenite/ferrite interface facets along the ferrite grain boundaries. In order to minimize the interfacial energy, ferrite grain boundaries in the vicinity of these facets migrate. Widmanstätten austenite laths have an orientation relationship with the ferrite grain into which they grow. The nucleation of Widmanstätten austenite only on one side of a ferrite grain boundary resulted in its straightening. The nucleation of Widmanstätten austenite laths on both sides of the ferrite grain boundary resulted in zig-zag shape of this boundary.

- Heavy precipitation of complex sulphides developed in the $\delta$-ferrite, grain/subgrain ferrite boundaries and ferrite/austenite interfaces. Majority of fine sulphides corresponded to the $\mathrm{Cr}_{2} \mathrm{CuS}_{4}$ phase. Needlelike precipitates in the ferrite matrix were formed by cementite

- Decomposition of Widmanstätten austenite laths initiated with the formation of epitaxial ferrite resulting in a further enrichment of remaining austenite in carbon. The growth of epitaxial ferrite into the flat ferrite/austenite interface facets along ferrite grain boundaries resulted in a wavy shape of these boundaries. The final step of Widmanstätten austenite decomposition resulted in the formation of pearlite by diffusional mechanism or plate martensite by displacive mechanism. The fraction of retained austenite in the final microstructure of the belt-casted strip was very small (about $0.5 \%$ ).

\section{ACKNOWLEDGEMENTS}

This paper created with the financial contribution of the projects Student Grant Competition "SP2020/58 Development of methods of structural analysis, testing of mechanical properties and non-destructive testing of advanced materials", "SP2020/39 Specific research in the metallurgical, materials and process engineering "and" and the project No. CZ.02.1.01/0.0/0.0/17_048/0007373

"Damage Prediction of Structural Materials" within the Research, Development and Education Operational Programme financed by the European Union and from the state budget of the Czech Republic.

\section{REFERENCES}

[1] GE, S., ISAC, M., GUTRIE, R. I. L. Progress in Strip Casting Technologies for Steel. Technical Developments ISIJ Int., 2013, vol. 53, no. 5, pp. $729-742$.

[2] SONG, H. Y., LU, H. H., LIU, H. T., LI, H. Z., GENG, D. Q., MISRA, R. D. K., LIU, Z. Y., WANG, G. D. Microstructure and Texture of Strip Cast Grain-oriented Silicon Steel after Symmetrical Asymmetrical Hot Rolling Steel Research Int, 2014, vol. 85, pp. 1477 - 1482.

[3] SONG, H. Y., LIU, H. T., WANG, G. D., JONAS, J. J. Formation of Widmanstätten Austenite in Strip Cast Grain Oriented Silicon Steel. Metallurgical and Materials Transactions A, 2017, vol. 48, no. 4, pp. 1959 - 1968.

[4] ZIN, J., HILLERT, M., BORGENSTAM, A. Morphology of Proeutectoid Ferrite. Metallurgical and Materials Transactions A, 2017, vol. 48, pp. 1425 - 1443.

[5] PERELOMA, E., EDMONDS, D. V. Phase Transformations in Steels. Vol 1: Fundamentals and Diffusion Controlled Transformations. Oxford: Woodhead Publishing Limited, 2012.

[6] OHMORI, Y., NAKAI, K., OHTSUBO, H., ISSHIKI, Y. Mechanism of Widmanstätten Austenite Formation in $\delta / \gamma$ Duplex Steels. ISIJ Int., 1995, vol. 35, pp. 969 - 975.

[7] AMEYAMA, K., WEATHERLY, G. C., AUST, K. T. A Study of Grain Boundary Nucleated Widmanstätten Precipitates in a Two-Phase Stainless Steel, Acta Metall. Mater., 1992, vol. 40, pp. 1835-1846.

[8] BHADESHIA, H. K. D. H., HONEYCOMBE, R. W. K. Steels: Microstructure and Properties, 4th edition. Oxford: Butterworths - Heinemann, 2017.

[9] VODÁREK, V., REIP, C. P., VOLODARSKAJA, A. Formation and decomposition of Widmanstätten austenite in GOES belt-casted strips. IOP Conf. Ser.: Mater. Sci. Eng. Beijing: IOP Publishing, 2019, vol. 668.

[10] VODÁREK, V., VOLODARSKAJA, A., MIKLUŠOVÁ, Š., HOLEŠINSKÝ, J., ŽÁČEK, O. Precipitation Reactions in a Copper-Bearing GOES. Procedia Materials Science, 2016, vol. 12, pp. 77-82. 